•论坛・

\title{
推进生物多样性跨境区域保护的中国实践
}

秦天宝 ${ }^{*}$, 袁昕

武汉大学环境法研究所, 武汉 430072

摘要: 生物多样性跨境区域保护作为《生物多样性公约》及 “爱知目标” 关注的重点内容, 已成为国际社会环境共治的前沿领 域。中国出于回应生态需求、履行《生物多样性公约》义务及坚持人类命运共同体理念的目的, 坚持生物多样性跨境区域保 护探索，推进该领域国际规则体系的建构, 形成多重层级合作共治的组织结构并产生联合执法、信息交流及合作管理的特色 合作机制，在实践中取得了一定成效。但生物多样性跨境区域保护的中国经验距离形成区域共识乃至全球方案仍有较大差距， 其原因一方面由于部分邻国合作意愿不强、合作能力不足等外部制约因素, 另一方面源于法律依据存在缺位、合作架构缺乏 联系、合作范围太过狭窄的内部运行缺陷，需通过把握多方共同利益基础及帮助提升他国能力建设克服外部障碍，围绕补充 法律规制体系、制定国家整体战略方案及扩充合作保护范围优化现有方案，以推进生物多样性跨境区域保护中国实践的进一 步发展。

关键词: 生物多样性公约; 爱知目标; 生物多样性; 跨境保护

秦天宝, 袁昕 (2021) 推进生物多样性跨境区域保护的中国实践. 生物多样性, 29, 220-230. doi: 10.17520/biods.2020104.

Qin TB, Yuan X (2021) China's practice of promoting biodiversity conservation in transboundary areas. Biodiversity Science, 29, 220-230. doi: 10.17520/biods.2020104.

\section{China's practice of promoting biodiversity conservation in transboundary areas}

Tianbao Qin ${ }^{(1)}$, Xin Yuan

Research Institute of Environment Law, Wuhan University, Wuhan 430072

\begin{abstract}
Background: As one of the key components of the Convention on Biological Diversity and Aichi Biodiversity Targets the protection of transboundary biodiversity areas has become a prominent issue in international environmental governance. To respond to ecological needs, fulfil the obligations of the Convention on Biological Diversity, and adhere to the concept of a community with a shared future for humankind, China seeks to enhance transboundary protection of regional biodiversity. This includes establishing an international rule system in this field, forming a multi-level cooperation governance organization structure, and producing special cooperation mechanisms for joint law enforcement, information exchange, and cooperative management. These actions have achieved practical outcomes in certain instances.

Problems: There is still a need to form a regional consensus and a global resolution for transboundary biodiversity conservation in China. First, progress has been delayed due to external constraints, such as some nations' unwillingness or insufficient capacity to cooperate. Second, internal operational deficiencies, such as the lack of a legal basis, the lack of a linkage to a cooperation structure, and the narrow scope of coordination, has also delayed progress.

Recommendations: To promote further development of China's practice of transboundary biodiversity protection, there should be understood the foundation of multiple parties' interests and aiding other nations to improve their capacity to overcome external obstacles, increased focus on supplementing the legal and regulatory system, formulating an overall national strategic plan, and expanding the scope of cooperative protection to optimize the existing plan.
\end{abstract}

Key words: Convention on Biological Diversity; Aichi Targets; biodiversity; transboundary protection

收稿日期: 2020-03-19; 接受日期: 2020-06-04

* 通讯作者 Author for correspondence. E-mail: fxyqtb@whu.edu.cn 
生物多样性跨境区域保护是指出于自然保护 地连通性、一体性及跨境区域生物多样性整体保 护、就地保护的考虑, 各国跨越政治边界, 通过跨 境自然保护区、生物廊道等方式, 针对边境地区的 典型生态系统展开双边或多边的合作保护机制。跨 境区域保护作为生物多样性国际合作保护领域的 探索, 已在全球范围内多有实践。2012年, 非洲博 茨瓦纳、安哥拉、纳米比亚、赞比亚及津巴布韦五 国签署国际合作协议，携手建立了世界上最大的自 然保护地一一卡沙跨界保护区。自20世纪90年代起, 中国也相继与老挝、越南、俄罗斯等国建立了生物 多样性跨境合作保护关系。这些举措在一定程度上 避免了因栖息地破碎化、跨界盗猎活动所导致的生 物多样性丧失, 对于物种种群、生态系统及遗传资 源的保护具有重要意义。

经过多年的发展, 生物多样性跨境区域保护已 经作为修复自然生境、维护保护区连通性及一体化 的实践方案得到了国际认可, 也为实现爱知生物多 样性目标提供了宝贵经验。2021年，《生物多样性 公约》(以下简称《公约》) 第十五次缔约方大会将 在中国举办，大会将审议“2020年后全球生物多样 性框架”, 并在爱知目标的基础上重新界定2030年 全球生物多样性新目标(CBD/WG2020/2/3)。在这 一 背景下, 本文围绕生物多样性跨境区域保护的意义 展开研究, 梳理我国跨境区域保护的历史沿革和发 展现状, 提出我国生物多样性跨境区域保护的整体 经验方案, 结合内外部视角对不足之处进行分析并 提出建议, 以期为生物多样性国际合作保护的进一 步发展提供参考。

\section{生物多样性跨境区域保护的意义}

\section{1 生态维度: 融合跨境生态系统保护的边界} 割裂

跨境生态系统的跨界属性决定了其完整性与 边界划分存在着天然矛盾。各国针对跨境生态系统 施以不同的理解方式、保护力度和管护模式, 彼此 割裂的管护模式导致了生物多样性整体保护的多 重困境。(1)生态系统内部连通性受限。国家边界将 跨境生态系统从地理空间加以分割, 使得自然生境 与栖息地呈现破碎化状态(姚爱静和何建勇, 2018), 从而导致生态系统内部结构和运行规律的破坏。生 态系统的连通性遭到干扰, 连带影响物种的行为模
式和生境分布，生态系统的整体保护失去基础。(2) 物种种群迁徙遭受干扰。国家边界的管控在实践中 多伴随着岗哨、铁丝网、围栏等人工阻隔物(王亚宁, 2019), 一些动物种群有根据季节变化按固定路线 迁徙的习性, 漫长的物理封锁线阻隔了它们的迁徙 路线, 开辟新路则伴随着极大的生存风险, 物种种 群保育受到极大挑战。(3)共有遗传资源管护缺位。 跨境生态系统存在着多种各国共有的遗传资源, 但 各国针对这类资源管护规制力度不同，从而为遗传 资源的利用方提供了低成本的开发选择。国家边界 的存在驱使利用方集中开采区域内某一生境斑块 的生物资源, 这使得遗传资源的保护失去整体意义, 也不利于生物系统内部遗传信息的传递。

对此, 生物多样性跨境区域保护跳出界限的桎 梏, 将跨境生态系统视为统一实体进行合作保护, 促使系统内部生境斑块相连、栖息地恢复; 移除区 域内部封锁，开放物种种群迁徙空间; 统一管护域 内生物资源，避免资源流失，可视为破除跨境生态 系统保护困局的上佳选择。

\section{2 法律维度: 满足《公约》设定的区域保护要求}

自1992年《公约》发布以来，《公约》缔约方 大会一直坚持着对于生物多样性跨境区域保护的 探索，这一领域的内容不仅体现在《公约》正文之 中，也散见于保护区工作组议程和爱知生物多样性 目标的设立。

首先，《公约》序言部分强调“生态系统和自然 生境的就地保护是保护生物多样性的基本要求”, 并于第 8 条明确指出 “缔约国应尽可能建立系统性 的保护区以满足特定地区生物多样性保护的需求, 确保保护区内外的生物资源得到持续保护，增进保 护区邻接地区的保护，加强合作以保障上述目标的 达成”; 其次, 《公约》缔约方大会针对保护区相关 争议议题在休会期间特设持续讨论谈判工作组(张 丽荣等, 2009)。2006年3月, 保护区工作组首次会议 报告将“建立和加强区域网络和跨界保护区”列入缔 约国保护区工作执行进展的评价矩阵, 并将评估标 准和关键评估问题设置为建立区域网络和跨界保 护区而采取的措施、纳入区域网络的保护区的数量 或百分比、跨界保护区的数目和地点三个方面 (Nigel et al, 2005)。最后，跨境区域保护被列入《全 球生物多样性保护战略规划(2011-2020)》20个纲要 性的目标(爱知目标)。爱知目标第11项规划了跨境 
区域保护的理想形态, 提出了建设连通性好的区域 保护区系统并将其融入到更广阔的陆地景观的具 体要求。

\section{3 价值维度：提升人类命运共同体理念的区域} 共识

生物多样性跨境区域保护的价值追求与我国 倡导并践行的人类命运共同体全球价值观不谋而 合。首先, 跨境区域保护符合合作共赢的价值内涵。 近代以来国际社会处于平稳发展的时期, 合作发展 逐渐成为各国交往交流的前提。生物多样性跨境区 域保护基于不同国家平等对话的交流基础, 出于生 物多样性保护的共同目的, 追求生态恢复、环境优 美的共同价值目标, 通过共同努力以破除单一国家 无法解决之生态矛盾, 是对人类命运共同体理念的 上佳诠释。其次, 跨境区域保护切合国际法“人类共 同利益”原则的价值追求。“人类共同利益”原则和人 类命运共同体理念交汇于共同的目标价值一人 类整体利益, 这一价值向度在国际环境合作领域尤 为凸显(李寿平, 2020)。在跨境合作议题方面, 《公 约》各缔约国已达成将人类整体利益置于价值衡量 首位的共识, 根据生态条件制定具体合作政策, 在 充分尊重彼此主权范围的基础上展开谈判(邹玥屿 等, 2017)。最后, 跨境区域保护符合生态发展的价 值特征。人类共同体理念的生态发展方式与可持续 发展原则息息相关, 并共同投射在生物多样性保护 的领域(秦天宝, 2006)。在这一领域内, 生态发展的 价值特征并不单体现在传统的绿色生产、减少对生 境影响以实现生物多样性保护实效, 还凸显在积极 参与国际环境治理、承担国际义务等方面。

\section{生物多样性跨境区域保护中国实践的现状}

\section{1 中国生物多样性跨境区域保护的发展历程和 整体现状}

我国幅员辽阔，生物资源种类丰富，自然条件 复杂多样, 是世界上生物多样性最富集的 12 个国家 之一(秦天宝, 2007), 就国内各地的分布情况来看, 尤以边境地区富集程度为甚。以西南边境云南省为 例, 据《中国生物物种名录2020版》 (Www.sp2000. org.cn)最新统计, 我国境内现存54,359个动物物种, 37,793 个植物物种, 云南省内共有 11,283 个动物物 种, 占比 $20 \%, 19,268$ 个植物物种, 占比 $50 \%$ 。就全 球尺度来看, 根据生物多样性热点地区(hotspot)评
估标准, 全球 25 个生物多样性热点地区有 4 个位于 我国西北及西南边境线上(柳江等, 2015), 生物多 样性跨境区域保护势在必行。由此, 我国在生物多 样性跨境区域保护领域展开了长期探索, 其发展历 程可大致分为三个阶段。

第一阶段是1992-2004年(专项合作-框架建立 时期)。我国自1992年加入 《公约》后开始尝试在边 境区域推进森林防火、渔业资源保护、生态监测等 生物多样性专项合作。如1992年, 中国虸腊县与相 邻老挝6县签订《联合防止中老边境地区森林火灾 协议书》; 1995年, 中国和俄罗斯两国政府签订《中 俄森林防火联防协定》、1996年签订《中俄在兴凯 湖建立禁渔区的协定》等。在专项合作的进程中, 我 国与陆上邻国总结合作经验, 选取具有保护典型性 及迫切性的跨境生态系统, 并以条约协定的形式界 定合作管护范围及责任, 生物多样性跨境区域保护 的倠形一一跨界自然保护区得以建立。1994年, 中 国、蒙古、俄罗斯正式签订《关于建立中、蒙、俄 共同自然保护区的协定》, 设立“中蒙俄达乌尔国际 自然保护区”。1996年, 中俄两国政府签订《兴凯湖 自然保护区协定》。

第二阶段是2004-2017年(全面深化合作时期)。 在这一阶段, 生物多样性跨境区域保护在原有的合 作基础之上进一步发展，跨境区域保护类型、方式、 范围、战略地位都得到了扩充和提升。2005年, 大 湄公河次区域环境部长会议审核通过“大沑公河次 区域核心环境与生物多样性走廊计划”项目; 2006 年, 中俄两国签署《中俄联合声明》, 成立中俄环 保合作分委会, 并在合作机制下设立跨界自然保护 区和生物多样性保护组, 指导和促进双方跨境区域 生物多样性保护; 2009年, 西双版纳自然保护区管 理局与老挝南塔省签署《中老跨边境联合保护区域 项目合作协议》，在西双版纳尚勇镇及老挝南塔楠 木哈建立中老跨境生物多样性联合保护区域, 2012 年再与老挝丰沙里和乌多姆赛两省签订合作协议, 扩大跨境生物多样性联合保护区域范围; 2010年, 大沣公河次区域核心环境项目一一曹邦(越南)一广 西(中国)跨境生物多样性保护廊道规划实施, 2015 年, 中国广西与越南高平签署生物多样性保护合作 谅解备忘录, 巩固合作成果, 扩大合作范围。此外, 在这阶段我国对包括跨境区域保护在内的生物多 样性保护愈发重视, 并将其提升至国家战略高度。 
2010年我国环境保护部发布的《中国生物多样性保 护战略与行动计划》(2011-2030年)、2015年发布的 《中国生物多样性保护优先区域范围》及2016年国 务院印发的《全国生态保护“十三五”规划纲要》都 对生物多样性跨境区域保护有专门规定。

第三阶段是2017年至今(转型整合时期)。2017 年, 中共中央办公厅、国务院办公厅印发《建立国 家公园体制总体方案》、2019年印发《关于建立以 国家公园为主体的自然保护地体系的指导意见》, 标志着我国境内所有自然保护地迈向整合转型期, 同时也标志着跨境区域生物多样性就地保护进入 了新的阶段。在首批规划的10个国家公园体制试点 内, 东北虎豹国家公园位于边境地区, 承接了生物 多样性跨境区域合作的功能任务。2019年, 东北虎 豹国家公园管理局和“雪松溪谷”国家自然生物圈保 护区与 “豹之乡”国家公园联合行政领导机构签订 《关于虎豹保护合作的谅解备忘录》(http://www.fo restry.gov.cn/main/72/20190705/094558488858247.ht $\mathrm{ml})$ 。

截至目前, 我国在东北地区设立了三江、八岔 岛、洪河、兴凯湖、达㐘湖 5 个双边或多边跨界自 然保护区, 规划在建的有汪清、珲春两个跨界自然 保护区; 在西南地区设立了中越跨境生物多样性景 观和廊道、中老跨境生物多样性联合保护区域两个 双边跨境生物多样性保护区, 规划建设的有高黎贡 山中缅联合保护区(李正波, 2017)。不同区域的跨界 自然保护区也承担着保障濒危珍稀物种自由迁徙、 栖息地恢复的重要功能, 中俄、中蒙、中老、中越4 个限定跨境生态系统分别维护着东北虎(Panthera tigris altaica)、黄羊(Procapra gutturosa)、丹顶鹤 (Grus japonensis)、亚洲象(Elephas maximus)、东黑 冠长臂猿(Nomascus nasutus)等特有物种的种群存 续。此外, 我国在生物多样性跨境区域保护中形成 了专项保护-生态廊道(小片区跨界保护区)构建一跨 境生态系统整体保护的发展逻辑, 并在实践中创新 合作机制, 总结发展经验, 业已形成符合中国特色 的生物多样性跨境区域保护方案。

\section{2 中国生物多样性跨境区域保护的主要成效}

在具体成效方面, 生物多样性跨境区域保护的 贡献突出表现为生态系统恢复和珍稀濒危物种拯 救两个层级。生态系统恢复是指通过干预方式促使 退化生态系统恢复为自然生态系统的过程, 其恢复
目标和评价指标的关键在于生态系统服务和生物 多样性的恢复效果。经研究分析, 以植被重建为主 的直接干预方式对于生态系统服务和生物多样性 的恢复效果最为明显, 在陆生和热带生态系统内则 更为突出(吴舒尧等, 2017)。在濒危物种种群拯救领 域, 最直接有效的方式为打击捕猎、保障栖息地完 整性和连通性、避免生境斑块的破碎化(田瑜等, 2009)。基于此, 我国在特定跨境区域开展植被恢 复、生态廊道建设、联合巡护等活动, 取得了一定 实效。

在我国广西和越南高平交界区域，中越双方针 对东黑冠长臂猿栖息地恢复展开联合调研, 拟定恢 复技术手册, 并提出在 8 个地区优先恢复植被。而后, 中方根据栖息地环境现状和恢复要求笁选树种, 并 开始在 4 个试点地区栽种榕树 (Ficus)、酸菄 (Choerospondias axillaris)、蚬木(Excentrodendron) 等食源树(蒋林林, 2018)。截至目前, 广西已组织开 展两次栖息地恢复活动, 共计提供苗木 11,000 余株, 恢复栖息地面积近千亩, 并持续定期进行生态监测 和联合保护活动, 有效降低了东黑冠长臂猿栖息地 的破碎化程度, 扩大了其生境范围。根据最新的调 查结果, 该区域东黑冠长臂猿由初次联合普查时的 18群110只, 增加至22群136只(http://sthjt.gxzf.gov. cn/ztzl/rdzt/ydwjlzxzl/ygzdt/t5575880.shtml)。

在云南和老挝交界区域, 中老生物多样性跨境 区域合作保护机制已相对成熟, 双方开展的信息交 流、防火防猎、廊道建设等活动取得了示范效应, 促使合作范围不断扩大。目前, 中老双方在边境线 上建立的“中老跨境生物多样性联合保护区域”长度 已达220 km、面积 20万ha (https://www.ynmh.gov.cn /84.news.detail.dhtml?news_id=30805); 亚洲象种群 数量持续稳定在 70 余头, 区域内象群基本实现了自 由流通(吕婷等, 2019); 其他物种类型数量也持续 上升, 在建立跨境保护区前, 西双版纳州内哺乳类 动物共99种, 保护区建立后则增长为129种, 并且 发现了3个新亚种(罗杰斯, 2020)。

在我国和俄罗斯交界区域, 双方重点合作目标 为保障生态系统连通性和打击盗猎活动。近年来, 随着保护区数量和范围的扩大, 中俄跨界自然保护 区有连成一片的发展趋势, 当地物种数量持续恢复, 野生东北虎开始逐渐迁徙至我国境内。据中俄边境 保护区监测数据显示, 当地 2018 年野猪(Sus scrofa) 
密度为1.91只 $/ \mathrm{km}^{2}$, 比2011年增加了 1.34 只 $/ \mathrm{km}^{2}$, 而 野猪等动物正是野生东北虎的主要食物 (http://linye.jlcity.gov.cn/xwdt/lyxx/201912/t2019122 5_721789.html)。2020年, 黑龙江太平沟国家级自然 保护区发现 4 只野生东北虎, 其中2只开始在保护区 生活, 并开始领地巡查(http://www.hlj.gov.cn/zwfb/ system/2020/04/05/010923217.shtml)。

\section{生物多样性跨境区域保护中国实践的经}

在研究基础尚且薄弱的生物多样性跨境区域 保护领域, 我国具备原生属性和创新价值的治理方 案为全球生态治理提供了可参考的经验，日益成熟 的治理范例也为爱知目标的早日实现提供了土壤。 纵观我国生物多样性跨境区域保护的现有成果, 可 以总结为以法律规则体系为依托、以多层合作机制 为基础、以特色实践领域为内容的中国方案。

\section{1 以法律规则体系为依托}

生物多样性是国际环境治理关注的热点区域, 跨境区域保护作为其中最为前沿的议题亟需建立 起与之配套的国际规则体系。规则建构的稳定性来 源于法律外观，国际法视野下全球性问题的传统解 决范式是通过国际合作与交流形成具有普遍意义 的国际认知(黄进, 2017), 在此基础上构建具有约束 力的国际规制, 使之成为各国共同遵循共同践行的 一般准则, 最终由各国转化为国内法加以落实。对 这一领域的法律文件加以梳理, 可以分为国际公 约、双边和多边条约、国际软法文件、国内立法衔 接 4 个层次。

(1)国际公约。如前文所述， 《公约》通过指导 性条款的设置和不带有强制性效力的技术文件引 导各国开展跨境区域保护行动, 鼓励各国主动进行 跨境区域保护探索。我国以公约要求为指引, 积极 建立跨界自然保护地合作项目, 并将其列入生物多 样性就地保护行动规划之中。此外, 我国也在生物 多样性相关的国际公约中探寻跨境区域保护的连 接点, 不同视角的相关国际规则设置为跨境区域保 护提供了有益的参考。如我国1985年签署的《保护 世界自然与文化遗产保护公约》提出在尊重缔约国 主权和相关遗传财产权的前提下承认跨境自然遗 产的存在，并指出国际社会均对其有保护的责任; 1992年签署的《关于特别是作为水禽生境的国际重 要湿地公约》提出各缔约方应针对跨越一个或多个
国界的湿地尽力沟通协调, 使跨界湿地与动植物得 到足够的保护政策。

(2)双边和多边条约。双边和多边条约是国际法 的重要溯源, 规定了缔约对象在特定领域的权利义 务关系，且对非缔约方不产生法律效力。我国在生 物多样性跨境区域保护探索初期，曾针对一些具有 典型性的跨境生态系统以双边和多边条约的法律 文件形式加以管护。如《中俄关于兴凯湖自然保护 区协定》，该协定提出以混合委员会的方式共同开 展兴凯湖跨境保护区的管护工作，将合作范围主要 界定在信息交流、科学研究、野外监测等方面，赋 予其法律效力(http://www.forestry.gov.cn/ghs/4609/ 20160120/838145.html); 《关于建立中、蒙、俄共 同自然保护区的协定》提出建立三方联合委员会， 委员会的职权范围界定在科研和合作保护活动的 批准和协调，增设了保障野生动物无碍通过边境的 条款，主要合作范围仍聚焦在科研和信息交流层面 (http://www.wendangku.net/doc/eb09e6d77c1cfad618 5fa706.html)。除此之外，《中蒙环境保护合作协定》 《中俄环境保护合作协定》也通过指导性条款的形 式规定了应在边境地区共同建立保护区的内容 (http://www.zrbhq.com.cn/index.php?m=content\&c=i ndex\&a=show\&catid=88\&id=189)。

(3)国际软法文件。国际软法文件虽然本身不具 有法律强制力，但由于其更新修改的便捷性、内容 设计的可试错性、作为国际“硬法”的补充性等特征， 在生物多样性跨境保护等新兴领域受到欢迎，其协 调国际关系、参与国际治理的实践表现也使其在一 定程度上起到了国际法律文件的作用(陈海明, 2010)。我国参与或参考的生物多样性跨境区域保护 的国际软法文件主要分为两类: 一类主要是国际组 织发布的参考文件或宣言。如世界自然保护联盟发 布的《为和平与合作的跨界自然保护地》《自然保 护地管理规划指南》; 国际自然保护地联盟发布的 《国际自然保护地联盟汗马宣言》等。另一类则是 双边或多边合作中我国参与或共同制定的计划文 件。如《中俄兴凯湖保护区2009-2010年合作计划》

《关于加强虎豹跨境保护合作哈尔滨共识》《关于 建立中蒙友好自然保护区的合作意向书》《关于中、 缅、老、越跨境地区生物多样性保护和减少非法野 生动物贸易的西双版纳宣言》等。

(4)国内立法衔接。在国内法层面, 生物多样性 
跨境区域保护的内容散见于《环境保护法》第二十 九条对具有代表性的自然生态系统区域保护的原 则性规定; 《野生动物保护法》第十二条对野生动 物栖息地和生存环境保护的规定; 《野生动物保护 法》第二十条对野生动物迁徙通道无碍通过的规 定。直至《云南省生物多样性保护条例》的出现, 跨 境区域保护首次以整体概念出现在我国法律规制 体系之内。《云南省生物多样性保护条例》是国内 首部生物多样性专门保护的省级地方性法规, 其第 十七条明确指出支持在生物多样性保护领域开展 国际合作并建立跨境保护合作机制; 第二十七条提 出保护生态系统完整性和连通性, 建立生态廊道。 这一条例的颁布对于云南省乃至我国整体生物多 样性跨境区域保护工作都具有重要的引领意义。

\section{2 以多层合作机制为基础}

从综合生态系统的视角来看, 生物多样性的保 护需考虑系统内的所有构成要素的特性和分布, 把 握各要素的运行方式及关联, 分类调整以驱使其转 化产生向心保护的整体动能。对跨境区域保护的整 体脉络进行剖析, 着眼于宏观层面的组织结构, 可 发现这一领域的调整向度可分为国家、地方政府、 社会组织三重维度。

(1)国家层级的组织形式。在生物多样性跨境区 域保护的场域内, 国家这一角色向外表现为规律运 行的整体系统, 其内在功能则在于中央政府参与国 际事务谈判、选择价值立场、承担国际义务、安排 行动战略。为了对接爱知目标所属的十年战略规划, 我国于 2010年9月发布《中国生物多样性保护战略 与行动计划》(2011-2030年), 提出自然保护区间联 通性和整体性保护的要求, 计划“在乌苏里江、内蒙 古达麥湖、内蒙古乌拉特、新疆阿尔泰、新疆夏尔 希里、新疆红其拉甫山口、西藏珠峰、图们江下游 等地区研究建立跨国界保护区”。2015年发布的《中 国生物多样性保护优先区域范围》定界划线, 将大 兴安岭、三江平原、长白山、呼伦贝尔、阿尔泰山、 天山-准噶尔盆地、喜马拉雅山东南部、横断山南 段、西双版纳、桂西南山地10个边境区域设置为生 物多样性保护优先区域, 要求各省加强边境地区生 物多样性的保护。在中央主管部门层面, 生态环境 部门通过部门规章或规划政策等形式对生物多样 性保护的具体内容加以规划, 在整体层面把握保护 进程。针对跨境区域保护, 生态环境部部长须定期
参加中俄总理会议环保分委会, 交流自然保护区跨 境合作经验, 规划跨境区域合作阶段路线; 参加大 湄公河次区域环境部长会议, 商议澜湄次区域生物 多样性保护走廊计划, 发表次区域环境部长会议联 合声明; 生态环境部对地方政府生物多样性工作实 效进行监管督查, 促使其跨境区域保护能力提升。

(2)地方政府层级的组织形式。在生物多样性跨 境区域保护的具体安排中, 地方政府的角色应视为 保护的基础支撑和实践力量。地方政府针对各省份 存在的生物多样性特征及跨境保护区分布, 因地制 宜地进行保护实践。如中俄依托环保合作分委会机 制, 推动黑龙江省林业厅与俄罗斯远东地区南部自 然保护区与国家公园联合会对接, 共同签订《关于 自然环境与自然资源保护和研究的跨境合作协议》, 协议计划在3年内开展联合反盗猎、信息交换、动 植物本底调查等活动; 云南、广西两个边境省份依 托于亚洲开发银行支持的大湄公河次区域核心环 境项目建立生物多样性跨境保护区域。云南省西双 版纳傣族自治州政府定期与老挝举办跨境生物多 样性联合保护交流年会, 签订合作备忘录, 重点关 注健全信息交流平台, 强化森林防火, 开展资源本 底调查、联合巡护和环境教育, 保护管理计划编制, 人才培养等合作内容(https://www.xsbn.gov.cn/105. news.detail.dhtml?news_id=67084); 广西省环境保 护厅与越南高平省自然资源与环境厅共同签署了 《生物多样性保护合作谅解备忘录》, 在监测评估、 联防联控等6个方面开始合作(http://sthjt.gxzf.gov.

cn/zwxx/qnyw/t3566150.shtml)。

(3)社会组织层级的组织形式。在我国, 社会组 织参与生物多样性跨境区域保护同时充当外部监 督与内部参与的角色, 主要功能为通过公众参与形 式向国内与国际双重级别的立法活动提供建议。以 中国生物多样性保护与绿色发展基金会(中国绿发 会)为例, 在国际法层面, 中国绿发会作为受邀机构 积极向《公约》建言献策, 2019年12月, 中国绿发 会支持的关于 2020 年后生物多样性连通性保护的 动议得到通过。在国内法层面, 中国绿发会也在为 以法律手段维护生态系统连通性贡献力量, 2020年 3月, 中国绿发会向“两会”提出将《生物多样性保护 法》列入年度立法计划的建议(http://www.cbcgdf.or g/NewsShow/5022/11640.html)。除此之外, 社会组 织也通过科研交流等活动方式开展对跨境区域保 
护的讨论, 会议记录或形成文件形式的报告可以充 当 “国际软法文件” 的作用, 为我国生物多样性保护 提供有益的参考, 如前文所述的 《国际自然保护地 联盟汗马宣言》，这一文件正是国际自然保护地联 盟年会的讨论结果。

\section{3 以特色实践领域为内容}

要实现生物多样性跨境区域保护的总体目标, 需厘清跨境区域生态系统的本质矛盾“对症下药”, 区域生态系统存在着盗猎活动猖獗、各国交流不 畅、管护措施及力度差异明显等先天缺陷, 针对这 些问题, 我国在实践中做出了解答。将跨境区域保 护微观层面的实体内容加以检视，可发现我国跨境 区域生物多样性保护的主要工作应归类为联合执 法、信息交流、合作管理三个方面。

(1)联合执法。边境区域的盗猎活动是对跨境生 物多样性保护最严重的威胁之一。在每个完整的生 态系统内都存在着经过自然选择的食物链, 一旦外 界活动对其中的一环加以影响, 最终的作用效果都 会反馈到整个生态系统之上。边境地区由于原真性 保存较好, 一般呈现为地广人稀、交通不便的特点, 这就为盗猎分子提供了广阔的逃逸空间，即使执法 人员找到踪迹线索，盗猎分子也可随时逃逸出国境， 执法人员固于政治边界的约束, 执法实效难以得到 保证。针对愈演愈烈的盗猎现象, 我国边境地区与 邻国采取了跨境联合执法机制。如中老跨境生物多 样性联合保护机制，该机制以充分信息交流和协调 为合作基础，定期巡护前，两国执法人员进行集中 性的培训, 对于珍稀动物辨别和行政执法措施加以 介绍，这一机制充分解决了双方执法人员交流不 畅、执法权不统一的矛盾, 在边境地区产生了极好 的生态效应反馈。随着联合执法的常态化, 跨境区 域的动物物种数量整体呈增长态势, 生物多样性逐 渐得到恢复。

(2)信息交流。生物多样性跨境区域保护合作领 域的信息交流并不完全等同于国际法意义上的信 息交换。信息交换代表着交换双方或多方都有可交 换的信息范围, 各方也会根据对方交换的信息量调 整自己的交换量，此间便沦为一个利益衡量的场所， 即便是通过规则设定的方式界定交换范围, 那么规 制制定的过程仍摆脱不了利益衡量的桎梏, 在这样 的条件下, 出于博栾的考虑, 各方都无法得到自己 的最优解。在我国的跨境区域保护合作实践中, 信
息互通的方式被替换为交流，沟通使参与方的需求 表达更为直接，交流也意味着协调，没有硬性规则 的设立使各方都拥有一定的自由裁量空间，也使各 方更容易达成共同利益需求的合意。跨境区域的地 理边界分割并不能反映到生态系统之中, 各国管护 方面对的是整体统一的生态系统，合作活动中信息 交流越顺畅，各方对于区域生态的理解就越一致， 合作保护的效果才能够体现。我国生物多样性跨境 保护的典型区域是东北和西南，西南地区合作趋于 常态化，东北地区合作不断扩展，这表明我国选择 了合理的交流机制。

(3)合作管理。跨境区域生物多样性管护措施及 力度的差异会直接反映在生态系统的变化上。简言 之, 人对生态系统的影响越小, 生态系统的原真性 就保存得越完好; 执法人员管护的力度越小，盗猎 或其他人类活动对生态系统的影响就越大。由此, 同一生态系统内各方管护政策的差异会造成生态 系统难以预测的变化。鉴于这一规律, 我国采用合 作管理的方式进行跨境区域生物多样性的保护，无 论是在我国已签订的双边或多边跨境自然保护区 协定，还是在地方省份自发形成的合作保护机制， 都以“联席管委会”或“合作备忘录”等柔性方式将跨 境区域的管理权赋予各方形成的共同体，在最大程 度上保障生态系统的整体性。

\section{4 生物多样性跨境区域保护中国实践存在的汇}

历经近三十年的发展，我国跨界自然保护区管 护合作机制的构建虽已形成独特的风格，但仍未形 成示范性的方案乃至区域共识，对实践领域进行考 察，可发现我国生物多样性跨境区域保护在外部发 展和内部运行方面均存在一些制约。

\section{1 生物多样性跨境区域保护的外部障碍}

(1)部分邻国缺乏开展生物多样性跨境保护的 合作意愿。首先，中印关系尚不稳定。生物多样性 乃至环境领域的合作应以互不干涉主权和领土完 整, 友好互信的外交观为基础，但目前中印关系存 在转为竞争乃至冲突的可能。印度与我国有2,000 $\mathrm{km}$ 的边境线，其中 $600 \mathrm{~km}$ 是争议地区，近些年来中 印边境冲突不断, 印度国内反华情绪强烈。在这样 的外交环境下很难推动需要跨越边界的环境合作。 其次，中亚地区非传统安全威胁增大。中亚诸国与 我国西北边疆地区拥有3,000 km的边境线，但该地 
区政治环境并不稳定, 宗教极端主义和国际恐怖主 义等非传统安全威胁突出, 是危害我国边疆地区安 全的重要源头。在这样的背景下开展模糊边界的环 境领域合作会给双方带来额外的维稳负担和安全 隐患。最后, 各方对于生物多样性保护的理解存在 偏差。从我国周边的整体发展形势来看, 有相当数 量的陆上邻国经济发展水平较差, 其国家战略普遍 呈现重视经济发展轻视环境保护的倾向, 这些国家 对生物多样性保护的理解和支持程度与我国存在 较大差异, 在该领域难以达成合意。

(2)部分邻国欠缺开展生物多样性跨境保护的 合作能力。首先, 特殊生态系统的恢复成本过高。 根据生态恢复理论, 生态系统退化的原因主要分为 气候变化和人类活动两种。我国西北边境地处高原, 多为荒漠生态系统, 其生态系统服务和生物多样性 退化受气候变化影响较大, 通过人为干预进行恢复 需要投入大量成本, 效果也无法保证。另外, 边境 区域有地广人稀的普遍特征, 提升该地区生态环境 质量和生物多样性并不能得到实际直接的收益反 馈, 考虑到中亚各国经济发展水平, 在边境地区进 行生物多样性保护确实难以为继。其次, 生物多样 性保护资金投入不足。相对来看, 我国的生物多样 性跨境保护工作在启动时期依赖于外部投资渠道, 中老跨境生物多样性联合保护区、中越跨境生物多 样性廊道建设都得到了亚洲开发银行的大力支持, 除此之外我国也仅启动了东北地区塞胗几个跨界 保护项目。换言之, 在没有外部投资渠道资金支持 的情况下, 大部分国家环境领域管护资金难以支撑 针对生物多样性跨境保护领域资金的持续投入。最 后, 跨境合作保护人才培养不足。生物多样性跨境 区域保护有别于普通自然保护地, 其规划、建设到 维持都需要专业人员投入(秦天宝, 2008)。在实践运 行层面, 跨境合作保护要在信息交流、环境监测、 资源识别等方面开展工作, 维护人员需要经过专业 培训, 而部分国家这一领域的人才培养能力相对较 弱。

\section{2 生物多样性跨境区域保护的方案缺陷}

(1)法律规则体系尚不充足。在生物多样性保护 领域, 包括《公约》在内的国际法律文件的规制条 文都具有指导性、鼓励性的色彩, 其意义在国内法 转换缺位的情况下难以得到体现。一些国际软法文 件提出了比较具体的要求, 但法律约束力的缺陷使
其权威性不足, 只能起到模糊的指引作用(秦天宝, 2011)。我国国内虽然有个别省份已经出台地方性法 规, 但其效力范围无法惠及全国, 在国际法-国内 法-地方法的法律结构体系中, 我国仍在国内法的 层次有所缺位。缺失承上启下的立法环节使得我国 生物多样性跨境区域合作保护呈现不稳定的发展 态势, 现有实践成果的价值也相应降低。我国生物 多样性保护事业对于国家级别的立法期盼已久, 跨 境区域保护的内容也不外如是。

(2)多层合作结构不成体系。我国生物多样性跨 境区域保护的组织结构的矛盾突出表现为各层级 主体“各自为政”, 在整体系统中定位模糊, 缺乏联 系。在现有的组织结构中, 中央政府既要负责对外 谈判, 在宏观层面根据国家义务制定行动规划, 也 要依据现有合作框架针对某一特定跨境区域对外 谈判, 界定合作内容, 不同定位的对外合作策略未 必一致, 且未有合作基础的规划区域也难以推进; 有合作基础的地方政府要在实践中继续探索合作 内容, 以没有法律约束力的协议书、谅解备忘录等 形式界定实际工作范围, 遵循的标准以满足实践需 求或投资方评估为主。换言之, 地方政府具体实践 并不一定和国家主管部门战略规划冲突, 但生物多 样性跨境区域保护是在“中央指导-地方遵循”的现 行框架内呈现一种自下而上的反馈机制; 社会组织 的定位更加混乱, 其矛盾点在于虽然不参与这一领 域具体实践但要与我国中央政府共同代表我国立 场参与公约谈判, 也在于国内提请具体立法建议时 与目前“自下而上”的取向错位。究其根源, 各层级 主体的混乱联系源自于我国生物多样性跨境区域 保护缺少清晰的主线遵循, 我国生物多样性跨境区 域保护工作推进已久, 但具体工作仍在满足地方实 践需求和履行公约要求的双重驱动下开展, 未能形 成整体系统的跨境区域保护统一战略思想。

(3)合作保护方式和领域亟待拓展。跨境生态系 统的新型生态问题(物种入侵、动植物疫情)与生物 多样性保护密切相关(万方浩等, 2002), 但在实践中 被排除到跨境区域保护的管护范围之外, 这些矛盾 集中表现为现有合作管护的范围设置太过狭窄。在 合作管护初期, 各国设立跨境自然保护地的直接目 的是共同应对无法单独解决的跨境突出生态问题, 如打击盗猎、保障动物种群迁徙等, 但出于新型合 作模式隐含的未知风险考虑, 经商讨选取了相对稳 
妥、范围限制的合作内容。随着时代的发展, 新型 生态风险威胁增大, 传统的合作机制已无法应对情 势变化。现有合作机制的成熟使环境共治的传统功 能趋于常态, 各国围绕生物多样性管护业已形成良 好的合作基础, 有能力也有动力在原有的规制范围 基础上扩大合作管护面向, 针对新时期特殊生态问 题讨论新型解决方案。

\section{5 展望和建议}

2020年是《公约》上一个十年战略规划的结束 之年, 虽然这份规划的很多内容没能完全实现, 但 通过经验的积累和时代的发展, 世界各国都对生物 多样性保护有了新的信心。我国在生物多样性跨境 区域保护方面仍具备巨大的提升潜力, 结合实践中 的进路选择，笔者有两方面的期望。

\section{1 克服生物多样性跨境区域保护外部障碍}

针对合作保护意愿不强的问题, 我国应聚焦寻 找共同利益点, 避免触及争议利益点, 致力于构建 双边乃至多边的共同利益基础, 在一定限度内推进 边境区域生物多样性的保护。面对中印边界争端问 题，在敏感时期我方应避免实体空间的具体合作， 而将合作形式转换为科研交流、信息交换等层面， 并寻求环喜马拉雅区域的尼泊尔、孟加拉国、缅甸 等国进行多方合作, 避免双方利益冲突。环喜马拉 雅区域是全球重要的生物多样性热点地区, 也是不 可忽视的生物多样性跨境割裂区域, 各国应秉持人 与自然生命共同体的观念尽力寻求合作保护的空 间; 面对非传统安全威胁的背景, 我国应在提高生 态检测标准、增强境内巡防频度的前提下开放固定 区域的生态廊道。雪豹(Panthera uncia) 是东亚山地 地区的旗舰珍稀物种，近年来由于生境破碎化、栖 息地退化等原因导致种群数量下降, 为了保障其生 境连通和受食迁徙, 我国可在其主要出没的阿尔泰 山区域构建生态廊道试点, 阿尔泰山区域位于北疆, 非传统安全威胁相对较小。各国对于生物多样性保 护理解的差异, 很大程度上也源自于保护能力的差 异, 我国可在帮助提升邻国生物多样性保护能力的 同时多承担保护义务, 体现负责任大国形象, 以实 际行动促使双方在合作中寻找共识。

针对合作保护能力不足的问题, 我国应认清自 身定位和时代特征, 以短期投资换长远回报, 积极 寻求和邻国乃至其他区域国家的合作机会, 积极帮
助其他发展中国家提升生物多样性保护能力, 以实 现协同保护、完善方案的目标。在具体实践中, 我 国应依仗“一带一路”倡议和亚投行等合作机制吸引 生态贷款，拓展生物多样性跨境区域保护的资金渠 道; 在合作中向其他国家提供技术援助和支持，定 期开展生态监测等项目培训, 建立生物多样性跨境 保护人才队伍; 组织科研专家实地考察跨境生态系 统，试点逐步恢复方案，合理界定跨境区域生物多 样性提升目标。

在生物多样性跨境区域保护的实践发展中, 我 国应抱有扬弃的态度学习其他区域的合作保护经 验，吸收其优势治理机制; 在保持自身多样性的同 时，通过法律保障体系的补足将体制机制进一步稳 固优化; 眼光应不局限于陆上邻国，而应逐步扩展 与海上邻国的交流合作，拓展创新合作模式。

\section{2 优化生物多样性跨境区域保护方案}

首先，加快《自然保护地法》和《生物多样性 保护法》的立法进程, 将生物多样性跨境区域保护 添加到法律条文中。这不仅满足《公约》所要求设 立的配套法律法规，也符合我国生态文明建设的 “五位一体”的总体布局。目前，生态文明建设任务 中的《自然保护地法》和《国家公园法》正在进行 立法论证工作，与其处于同等法律位阶的生物多样 性保护立法也应加快进度，以实现生态文明法律保 障体系的完整; 跨境区域保护作为自然保护地的特 殊形式符合生物多样性就地保护的基本价值目标, 《自然保护地法》的法律条文中应专门规定自然保 护地跨境合作的功能和目的。《生物多样性保护法》 与《自然保护地法》应成为我国生物多样性跨境区 域保护遵循的基本法, 有助于填补跨境区域保护国 内立法的体系结构，实现该领域法律体系的融贯性; 生物多样性跨境区域保护是生态文明建设战略与 人类命运共同体的有机结合，充分体现了 “绿水青 山就是金山银山”的发展理念。在环境发展和国际 合作的双重垂直领域加强法律规制，不仅有助于冲 破生态领域精细立法规制的桎梏，也能使我国生物 多样性跨界合作保护多样性、适应性的风格得以存 留, 进而驱动该领域的探索实践继续发展。

其次，在国家层面制定生物多样性跨境区域保 护的战略规划和实施方案。目前我国生物多样性跨 境区域保护的内容出于履行《公约》要求、回应邻 国或国际组织需求、满足区域保护实践需求等不同 
目标, 散落于生物多样性乃至生态保护的部分内容 之中, 呈碎片化。在国家层面明确生物多样性跨境 区域保护的核心思想和框架设计, 向外有助于我国 整理生物多样性跨境区域保护的中国方案, 为其他 国家乃至全球提供经验参考, 向内有助于整合生物 多样性跨境区域保护的整体系统, 理顺整体脉络, 明确中央、地方政府、社会组织在这一领域内的具 体功能和整体遵循，界定不同主体之间的配合方式， 并服务于我国生物多样性保护的整体目标。

最后, 扩大生物多样性跨境区域保护的合作范 围, 将生物安全等内容添加到合作保护的范畴, 推 动新条文内容的商讨和再签订。在生态环境利益和 人类整体利益被重视的新时代, 我们有理由相信出 于团结协作目标的环境共治内容能够再次达成共 识。我国应主动推动扩大新条约的签订方范围, 逐 步将双边条约合并为形成区域共识的多边条约, 并 以东北、西南两个方位为空间主体, 推进区域命运 共同体的形成。在具体合作机制范围和内容的扩充 层面, 可参考青海三江源国家公园的先例, 倡导将 原住民雇佣为生态环境的管护者, 既能够发挥其熟 悉环境的优势, 也能实现执法队伍的扩充; 遗传资 源丧失的最大敌人是生物剽窃(薛达元, 2015), 跨境 生态系统中的共有遗传资源保护应重点引导资源 及相关传统知识形成统一的获取和惠益分享机制, 共同打击生物剽窃行为, 维护区域各方共同利益; 外来物种风险的预防不仅要体现在防范对其他生 态系统的影响, 还要注意防止动植物疫情的传播, 应将传统边界的部分功能设置于整体生态系统的 新边界上, 以防外来物种的入侵和逸散。

\section{ORCID}

秦天宝 (D) http://orcid.org/0000-0003-4932-9213

\section{参考文献}

Chen HM (2010) The role of international soft law in the international legal order. Tribune of Social Sciences in Xinjiang, (1), 41-45. (in Chinese) [陈海明 (2010) 国际软 法在国际法律秩序中的作用. 新疆社科论坛, (1), 41-45.]

Huang J (2017) Study on Xi Jinping's global governance and international rule of law. China Legal Science, (5), 5-22. (in Chinese with English abstract) [黄进 (2017) 习近平全球 治理与国际法治思想研究. 中国法学, (5), 5-22.]

Jiang LL (2018) Apes call on the both sides of two countries - Report on the joint rescue of critically endangered
Eastern Black Crested Gibbon by China and Vietnam. Forestry of Guangxi, (1), 11-14. (in Chinese) [蒋林林 (2018) 两国猿声啼不住一一越两国联合抢救极度濒危 东黑冠长臂猿纪实. 广西林业, (1), 11-14.]

Li SP (2020) The vision of a community of shared future for mankind lead the reform of rule of international law: Logical implications and approach. Studies in Law and Business, 37(1), 44-56. (in Chinese with English abstract) [李寿平 (2020) 人类命运共同体理念引领国际法治变革: 逻辑证成与现实路径. 法商研究, 37(1), 44-56.]

Li ZB (2017) China and Myanmar jointly discuss biodiversity conservation and jointly issue a declaration: A record of the seminar on biodiversity conservation and sustainable development cooperation in the northern part of the Sino Myanmar border. Yunnan Forestry, 38(1), 20-23. (in Chinese) [李正波 (2017) 中缅共同研讨生物多样性保护 问题, 联合发表宣言一中缅边境北段生物多样性保护 与可持续发展合作研讨会记实. 云南林业, 38(1), 20-23.]

Liu J, Wu RD, He DM (2015) Transboundary eco-security regulation for geopolitical cooperation in land border areas. Progress in Geography, 34, 606-616. (in Chinese with English abstract) [柳江, 武瑞东, 何大明 (2015) 地缘合 作中的陆疆跨境生态安全及调控. 地理科学进展, 34, 606-616.]

Lü T, Zheng X, Zhu GF, Tang YJ, Jiang GL, Li ZL, Chen MY (2019) Dynamics analysis of Xishuangbanna Mengla Asian elephant population. Forestry Construction, (6), 91-96. (in Chinese with English abstract) [吕婷, 郑璇, 朱高凡, 汤永 晶, 蒋桂莲, 李正玲, 陈明勇 (2019) 西双版纳㔚腊亚洲 象种群数量动态分析. 林业建设, (6), 91-96.]

Luo JS, Sun P (2020) The role of China-Laos cross-border joint protection areas in biodiversity conservation. Journal of Green Science and Technology, (8), 38-39. (in Chinese) [罗 杰斯, 孙萍 (2020) 中老跨境联合保护区在生物多样性 保护中的作用. 绿色科技, (8), 38-39.]

Nigel D, Kalemani JM, Sheldon C, Sue S, Charles VB, Sarat BG (2005) Towards effective Protected Area Systems, An Action Guide to Implement the Convention on Biological Diversity Pro-gramme of Work on Protected Areas. Technical Series No.18. Secretariat of the Convention on Biological Diversity, Montreal, Canada.

Qin TB (2006) A new concept of international law "matters of common concern to mankind": A case study of the Convention on Biological Diversity. Law Review, (5), 96-102. (in Chinese) [秦天宝 (2006) 国际法的新概念“人 类共同关切事项”初探—— 以 《生物多样性公约》为例的 考察. 法学评论, (5), 96-102.]

Qin TB (2007) Biodiversity conservation: An international law perspective. Journal of the Party School of Jinan Municipal Committee of CPC, (1), 31-34. (in Chinese) [秦天宝 (2007) 生物多样性的保护: 国际法的视角. 中共济南市 委党校学报, (1), 31-34.]

Qin TB (2008) Study on characteristics of International 
Environmental Law. Journal of China University of Geosciences (Social Sciences Edition), 8(3), 16-19. (in Chinese with English abstract) [秦天宝 (2008) 国际环境 法的特点初探. 中国地质大学学报(社会科学版), 8(3), 16-19.]

Qin TB (2011) The emergence and development of International Law on Biodiversity Conservation. Jiang-Huai Tribune, (3), 103-108. (in Chinese) [秦天宝 (2011) 生物 多样性保护国际法的产生与发展. 江淮论坛, (3), 103-108.]

Tian Y, Wu JG, Kou XJ, Li ZW, Wang TM, Mou P, Ge JP (2009) Spatiotemporal pattern and major causes of the Amur tiger population dynamics. Biodiversity Science, 17, 211-225. (in Chinese with English abstract) [田瑜, 乌建国, 寇晓军, 李钟汶, 王天明, 牟溥, 葛剑平 (2009) 东北虎 种群的时空动态及其原因分析. 生物多样性, 17, 211-225.]

Wan FH, Guo JY, Wang DH (2002) Alien invasive species in China: Their damages and management strategies. Biodiversity Science, 10, 119-125. (in Chinese with English abstract) [万方浩, 郭建英, 王德辉 (2002) 中国外来入侵 生物的危害与管理对策. 生物多样性, 10, 119-125.]

Wang YN (2019) A study on the connotations of hard border. Journal of Boundary and Ocean Studies, 4(3), 81-93. (in Chinese with English abstract) [王亚宁 (2019) 浅析硬边 界的内涵. 边界与海洋研究, 4(3), 81-93.]

Wu SY, Huang J, Li SC (2017) Effects of different ecological restoration approaches on ecosystem services and biodiversity: A meta-analysis. Acta Ecologica Sinica, 37,
6986-6999. (in Chinese with English abstract) [吴舒尧, 黄 姣, 李双成 (2017) 不同生态恢复方式下生态系统服务 与生物多样性恢复效果的整合分析. 生态学报, 37 , 6986-6999.]

Xue DY (2015) On establishing the national synergy strategy for the implementation of international agreements related to biodiversity conservation. Biodiversity Science, 23, 673-680. (in Chinese with English abstract) [薛达元 (2015) 建立生物多样性保护相关国际公约的国家履约协同战略. 生物多样性, 23, 673-680.]

Yao AJ, He JY (2018) Ecosystem connectivity of Beijing Great Wall National Park. Greening and Life, (8), 44-46. (in Chinese) [姚爱静, 何建勇 (2018) 北京长城国家公园生 态系统连通性研究. 绿化与生活, (8), 44-46.]

Zhang LR, Cheng WJ, Xue DY (2009) Progress and trends for implementation of the Convention on Biological Diversity. Acta Ecologica Sinica, 29, 5636-5643. (in Chinese with English abstract) [张丽荣, 成文娟, 薛达元 (2009) 《生物 多样性公约》国际履约的进展与趋势. 生态学报, 29 , 5636-5643.]

Zou YY, Fu YL, Yang LR, Wan XL, Wang Y, Liu JX (2017) China and COP 15: A path for responsible environmental power. Biodiversity Science, 25, 1169-1175. (in Chinese with English abstract) [邹玥屿, 傅钰琳, 杨礼荣, 万夏林, 王也, 刘纪新 (2017) 中国与COP15一一负责任环境大国 的路径选择. 生物多样性, 25, 1169-1175.]

(责任编委: 徐靖 责任编辑: 时意专) 